The International Journal Of Engineering And Science (IJES)

|| Volume || 6 || Issue || 1 || Pages || PP 57-75|| 2017 ||

ISSN (e): $2319-1813$ ISSN (p): $2319-1805$

\title{
Digital Heritage Documentation Via TLS And Photogrammetry Case Study
}

\author{
Ahmad Baik \\ Dept. of Geomatic Engineering, University College London, Gower Street, London, WC1E 6BT UK-Ahmad. \\ Ahmad.Baik.12@ucl.ac.uk/abaik@kau.edu.sa
}

In the last decade, several manual tradition measurement techniques were used to document the heritage buildings around the word; however, some of these techniques take a long time, often lack completeness, and may sometimes give unreliable information. In contrast, terrestrial laser scanning "TLS" surveys and Photogrammetry have already been undertaken in several heritage sites in the United Kingdom and other countries of Europe as a new method of documenting heritagesites. This paper focuses on using the TLS and Photogrammetry methods to document one of the important houses in Historic Jeddah, Saudi Arabia, which is Nasif Historical House, as an example of Digital Heritage Documentation (DHD).

Key Words: Heritage Documentation, TLS, Historical Jeddah

Date of Submission: 23January 2017

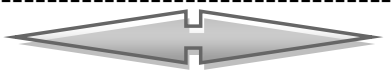

Date of Accepted: 05 February 2017

\subsection{Terrestrial Laser Scanning "TLS"}

\section{INTRODUCTION}

During the 2000s and since the technology has become more commercialised, one of the most popular technologies used to capture the 3-D complex structures to be modelled in the 3-D environment is terrestrial laser scanning (Budroni and Boehm, 2010). There are several reasons to use terrestrial laser scanning in Heritage Building Information Modelling and these relate to the high level of accuracy that laser scanning can offer, in addition to the time necessary to do the scans on the cultural sites. Besides, the most important reason to use TLS is that it can be used to measure the existing condition of buildings (Cheng and Jin, 2006; Macher et al., 2014). TLS can be described as an automatic measurement scheme that measures the 3-D co-ordinates based on the surface from the selected object. The generated data that is received from the laser scanning is then represented in point cloud form. Each of these points, according to Murphy (2012), have the "x, y and z coordinates" based on the scanned surface, also, the "laser ranger is directed towards an object by reflective surfaces that are encoded so that their angular orientation can be determined for each range measurement". These point clouds are described by Thomson and Boehm (2015) as the absolute minimal level of detail base (stylised as LoD 0) from which more data rich abstractions can be produced to represent higher levels of detail.

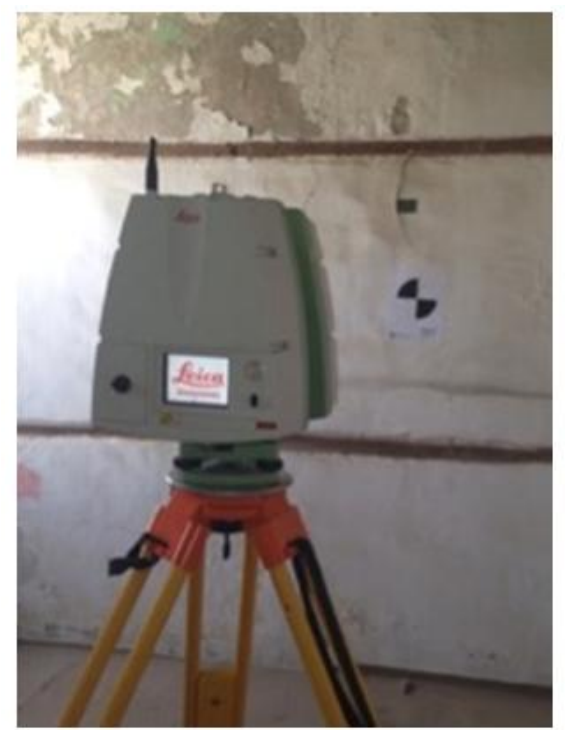

Figure 1: Leica laser scanning C10. 
Several laser scanning systems are available in the engineering market these days. On the other hand, as Murphy (2013) proposes, "there are three types of scanners suitable for metric surveys for cultural heritage", which are "time of flight scanners, triangulation and phase comparison".

The difference between these systems concerns the technique of how the scanner calculates the 3-D co-ordinate measurements. For instance, in the case of the triangulation type, the scanner uses the spot regarding the laser ray on the surface of the object, captured via one or more cameras (Murphy, 2013). In contrast, as Boehler et al. (2003) stated, "time of flight scanners calculate the range, or distance, from the time taken for a laser pulse to travel from its source to an object and be reflected back to a receiving detector".

Since 2009, the use of terrestrial laser scanning has been introduced as a common method for capturing the reality of the as built BIM projects (Arayici et al., 2009; Hichri et al., 2013; Huber et al., 2010; Volk et al., 2014). This was due to two main reasons (Backes et al., 2014); firstly, the endorsement of governments such as the UK and USA to focus on the issue of BIM, which was reflected in the increased use of laser scanning to capture reality (BIM Task Group, 2013), and secondly, the support of CAD vendors for the integration of point-cloud handling devices without plugins in their BIM tools, which resulted in a high demand for laser scanning.

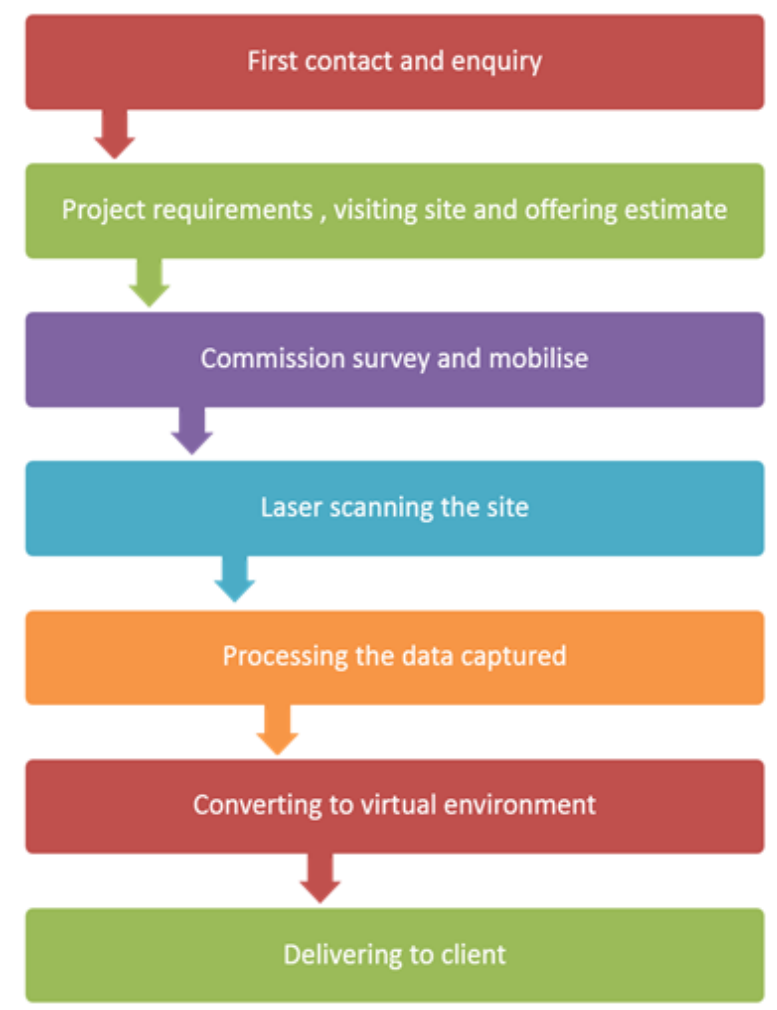

Figure 2: The typical laser scanning survey method.

\begin{tabular}{|c|c|c|c|}
\hline \multicolumn{2}{|l|}{ scoming spstem } & use & spicol oconocy / operoting none \\
\hline \multirow{3}{*}{$\begin{array}{l}\text { trierguation } \\
\text { based ertefact } \\
\text { scamens }\end{array}$} & rotation stape & $\begin{array}{l}\text { - scanning mall objects (that can be removed from ste) } \\
\text { - to produce data sucutie for a replica of the object to be made }\end{array}$ & SO micons $/ 0.1 \mathrm{~m}-1 \mathrm{~m}$ \\
\hline & arm mounted & $\begin{array}{l}\text { - scamine mall objects and smal surfaces } \\
\text { - can be performed on site I required } \\
\text { - can be usod to produce a replica }\end{array}$ & SO microns / Q.1m- Im \\
\hline & mirrontpram & $\begin{array}{l}\text { - samring small object surface areas in seu } \\
\text { - can be used to produce a replica }\end{array}$ & sbmm $10.1 \mathrm{~m}-25 \mathrm{~m}$ \\
\hline \multicolumn{2}{|c|}{ terrestrial time-olfight laser scamen } & $\begin{array}{l}\text { - to suney building tacades and interion, resulting in line drawings } \\
\text { (with supporting data) and surlace models }\end{array}$ & $\begin{array}{l}\text { 3-6mm at raves ip to severd } \\
\text { hunded metres }\end{array}$ \\
\hline \multicolumn{2}{|c|}{$\begin{array}{l}\text { terrestrial phave-comparison } \\
\text { laser scames }\end{array}$} & $\begin{array}{l}\text { - to survey buldine facades and interions resulting in ine drawing. } \\
\text { (with supporting data) and surface models - particularly where } \\
\text { napid data acquibition and high point density are required }\end{array}$ & c Smm at raves is to $50-100 \mathrm{~m}$ \\
\hline \multicolumn{2}{|c|}{ aiborne laser scaming } & - to map and prospect landicapes (nduding in forested areas) & $\begin{array}{l}\text { O.05m+ (depending on the parameters } \\
\text { of the suney) / } 100 m-3500 m\end{array}$ \\
\hline \multicolumn{2}{|l|}{ moble mapping } & $\begin{array}{l}\text { - to suney highways and ralways } \\
\text { - for cty models } \\
\text { - to montor coastal erosion }\end{array}$ & $10-50 \mathrm{~mm} / 100-200 \mathrm{~m}$ \\
\hline
\end{tabular}

Figure 3: Laser scanning techniques used for cultural heritage sites (Heritage, 2011). 


\subsection{Terrestrial Laser Scanning Data Processing}

Laser scanning usually captures a huge range of real time data, which is represented in 3-D co-ordinates, described as 'point cloud data', always collected from several scans locations. This is because it is usually impossible to scan the whole object in one scan. In that case, it is very important to register the different scan's data in order to locate all the 3-D point cloud data together via coordinate transformation (Cheng and Jin, 2006). While laser scanners can take a few minutes to scan millions of accurate 3-D points, there is enormous work involved in transporting this data into a 3-D model containing useable information. As Remondino (2003) explains, "dedicated software programs such as Leica cloud-works, Polyworks, AutoCAD, and RiScanpro have highly improved the processing, manipulation and analysis of vector and image data from the point cloud" and "all of these software platforms have combined algorithms for triangulation and surfacing of the point cloud".

\section{Data cleaning}

Once the scanner's point cloud is transferred, there are several suitable programs that can be used in the step that involves the evaluation and filtering of the point cloud data. The data evaluation can be described as a process of locating the overshoot and repeated zone when scanning and deciding whether to scan over. The data filtering can be described as reducing the noise, smoothing noise and resampling the data (Cheng and Jin, 2006). Each system from these laser scanners has its own software. For instance, Leica Cyclone ${ }^{\circledR}$ deals with the Leica laser scanning systems. Generally, the modelling process in Leica Cyclone ${ }^{\circledR}$ involves generating the best-fit geometric objects out from the point cloud. Leica Cyclone ${ }^{\circledR}$ has a number of object-suitable utilities for the user to select from, depending on the topology that comes out of the scanned point cloud.

\section{Point cloud registration}

The concept of point cloud registration is to combine a range of scan stations with different perspectives of the scanned object. According to Leica Geosystems (2006), "integration is derived by a system of constraints, which are pairs of equivalent tie-points or overlapping point clouds that exist in two Scan-Worlds". The registration method "computes the optimal overall alignment transformations for each component Scan-World in the registration such that the constraints are matched as closely as possible". There are several methods which can be used to register these scan stations by applying one of the two methods, or a combination of them, for example, target based or point cloud based (Mills and Barber, 2004; Rajendra et al., 2014). Using the Global Positioning System (GPS), the co-ordinates based on the laser scanner location can be determined, which can then, according to Cheok et al. (2000), "allow for the scans from each position to be brought into a common frame of reference in a global or project co-ordinate system". The first method; target based or target-to-target registration, is a registration between multiple point cloud scans and registered into a single point cloud through the use of control targets in the point clouds. Moreover, to achieve perfection and with minimum errors, three corresponding points, or more, at each point cloud registration must be in common between them. These points can be either natural or artificial targets. This technique is designed to offer the most accuracy inasmuch as the standards of survey net plan are respected (Pfeifer and Böhm, 2008). Despite natural targets being assigned manually, the artificial targets can be assigned automatically via employing certain algorithms. The automatic assigning procedure is subject to detecting certain shapes from targets, such as spheres or HDS black and white "BIW" targets. Figure illustrates a number of artificial targets that can be used. Some advanced algorithms, which can be used to identify correspondence in order to allow for a full automatic registration procedure are implemented in commercial programs such as Leica Cyclone (Abdelhafiz, 2009). The second method is the overlap or the cloud-to-cloud registration method, which involves aligning overlapping scans into a single point cloud through using a number of constraints that are nominated within the point cloud software, such as Autodesk Recap pro or Leica Cyclone model space. It is very important in this method that the selected features are matching in both registered modelspaces (Darie, 2014). The registration result can be used as a base frame of the geometry of the historic structure as in the research of Murphy (2012), which can then be modelled in different modelling software, such as Autodesk Revit, 3-D MAX, Sketch Up and AutoCAD.
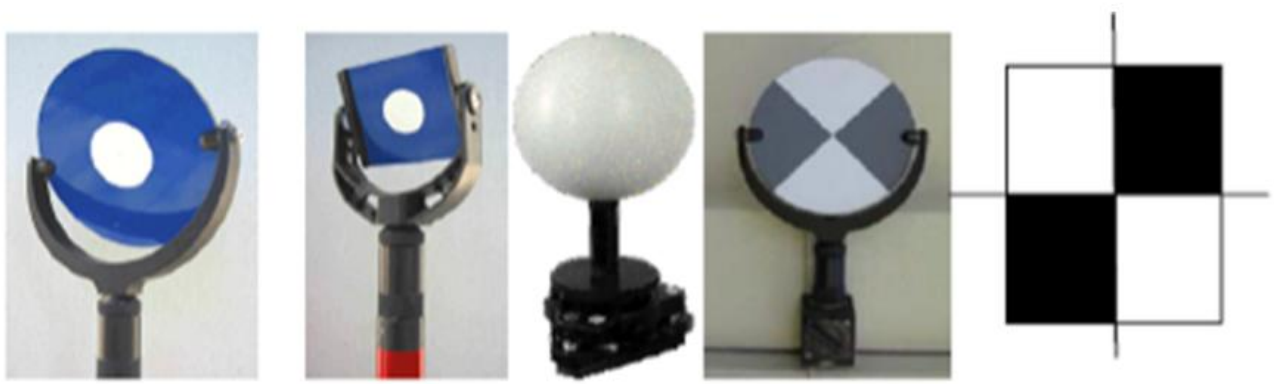

Figure 4: Different types of artificial targets used (Source: Abdelhafiz, 2009) 


\subsection{Combining Laser Scanning and Digital Images}

The new modern laser-scanning systems usually incorporate built-in cameras for capturing the photos, then the photos are applied to the point cloud to be coloured via linking the multi-image batch to the point cloud data.

As stated by Abmayr et al. (2005), "the RGB colour data from the images can be mapped onto range data by taking account of point translation, instrument rotation and perspective projection". For this, both the laser, as well as the camera, as pointed out by Murphy (2013), "must be correctly geometrically calibrated" and "the correction of the camera is presented to correct the distortion of camera lenses, and by mapping onto the point cloud any perspective contained in the images is removed".

Additionally, the HDR colour images "can be precisely mapped onto a geometric model represented by a point cloud, provided that the camera position and orientation are known in the coordinate system of the geometric model," (Beraldin, 2004).

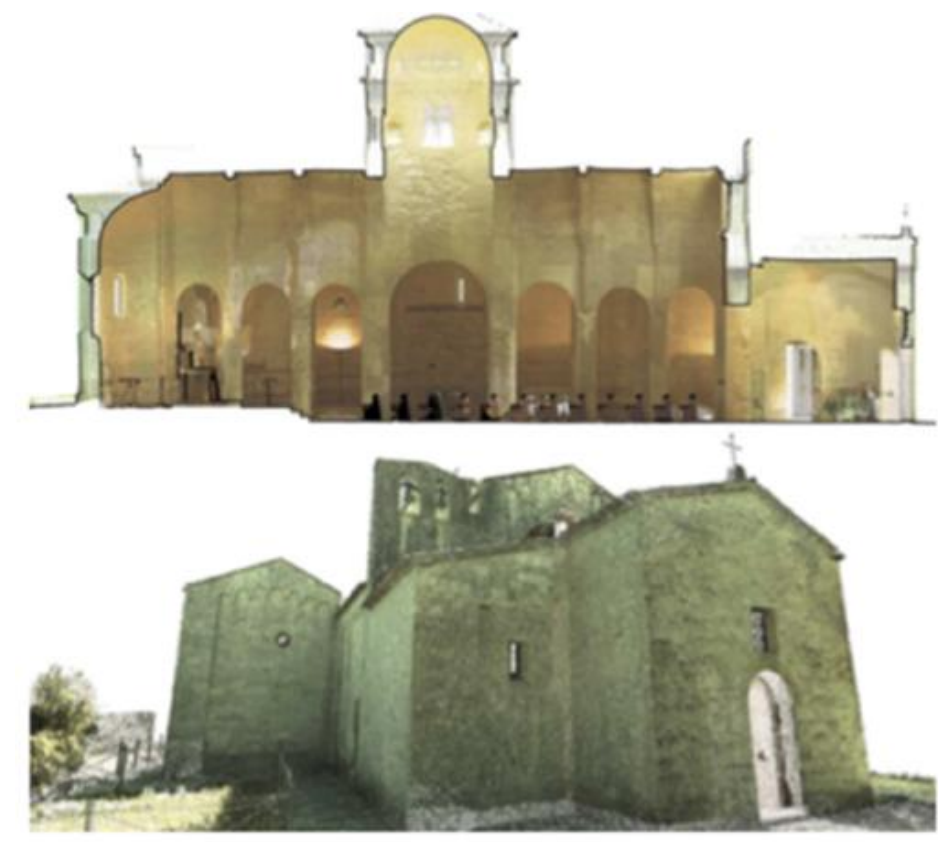

Figure 5: TLS survey of Church Santa Maria at Porto-Novo. Point cloud mapped with the RGB value of camera acquisition done by Quattrini et al. (2015).

\subsection{Level of accuracy}

Laser scanning is an advanced technology which can provide highly accurate data. According to Murphy, (2012) using laser scanning and Photogrammetry in the case of capturing the heritage structure can "meet with the accuracy and efficiency requirements for recording and surveying of historic structures and artefacts". However, accuracy can be affected by various of factors, for example, errors in the distance and the angle measurements, and in the algorithm for fitting the "spheres/targets" in the point cloud. Besides, according to Mechelke et al. (2007), "the influence of these errors cannot be determined separately". Some laser scanning equipment can have issues through reflectance out of certain materials, for example, marble and gilded façades.

It has been found in the examinations of the 3-D assessment in the field by Mechelke et al. (2007), that the range value (starting with the lowest to the highest deviation value), which is effected through the estimation accuracy of the instrument, as well as through the algorithm suitable for the sphere, shifted from $41 \mathrm{~mm}$ to $76 \mathrm{~mm}$ for the scanners of Trimble GX, Leica Scan Station, Faro LS 880HE and IMAGER 5006. In Mechelke et al.'s (2007) study, it can be observed that just the "time-of-flight" technique reached a methodical fluctuated up to $+6 \mathrm{~mm}$ within the derived distances.

The examinations of the accuracy, with reference to distance measurements in contrast with reference distances, presented evidently that the outcomes provided the accuracy requirement of the manufacturer, while the accuracy is somewhat unique for every instrument.It can be noted that the laser scanning accuracy determination is different than the total station, which cannot depend on a single target measurement and can be difficult to reproduce. However, focusing on objects through known properties within the laser scan volume, for example, reference spheres, can lead to a utilisation appropriate component that relates directly to the output model and its purpose. Rather than evaluating each point, the model can be evaluated (Thomson, 2016).

Additionally, according to the guide of the 3-D Laser Scanning for Heritage by (Heritage, 2011), both levels of accuracy and resolution of measurement are typically related to object size and the purpose of the laser survey, and 
there is no specific level required. However, the best answer for that, is "the best that you can do".

\subsection{Photogrammetry}

In some circumstances, the terrestrial laser scanning has some limitations, especially in the case of complicated sites and difficult areas being reached and further, for detailed structures and vignettes. Architectural photogrammetry or the close-range photogrammetry technique can offer a good solution for such issues, which can produce both orthoimage and linear drawings (Cheng and Jin, 2006). As Hanke and Grussenmeyer (2002) stated, architectural photogrammetry "is a technique for gathering information of the obtaining geometric, e.g. size, position, and shape of every object, which was imaged on photos before".

Recently, architectural photogrammetry and 3-D modelling methods have been rapidly advancing, with part of the focus being on developing new technology for the purpose of applying them to architectural heritage documentation. Current advances have allowed for semi-automated and automated solutions, based on Dense Stereo Matching (DSM) (Furukawa and Ponce, 2010; Hirschmuller, 2005) and Structure from Motion (SFM) (Agarwal et al., 2011, p. 20; Pollefeys et al., 2008; Vergauwen and Van Gool, 2006), to be presented commercially. Besides, they have an advantage over the web-based software through providing accurate results in order to obtain 3-D point clouds, as well as the textured mesh surfaces; such as Autodesk Recap® and PhotoModeler by Eos Systems Inc.

The full automation of the procedure of image orientation and matching has been shown to facilitate and speed up the data processing task that, in some cases, could be a never-ending process if performed manually. The dense cloud of 3-D points as a result, by itself, is typically not very useful. In this regard, a number of post-processing steps are usually carried out. This post processing often involves filling holes, filtering; smoothing, meshing/triangulation and sometimes NURBS patch conversion. A separate 3-D software program generally carries out these functions (Alitany et al., 2013).

Figure 6 shows an example of the Professor Grussenmeyyer project, which employed the architectural photogrammetry technique.
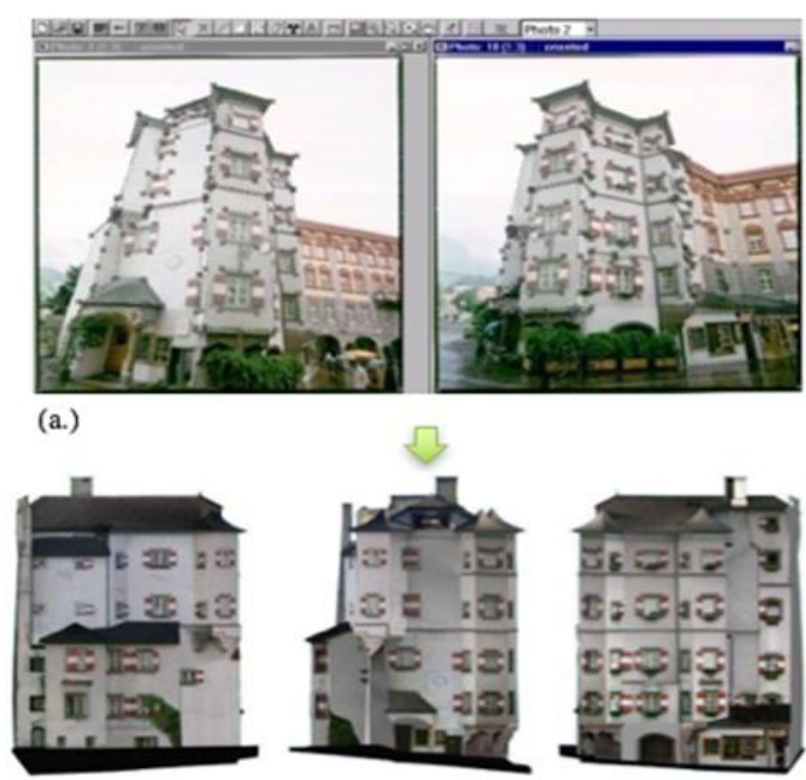

(b.

(c.)

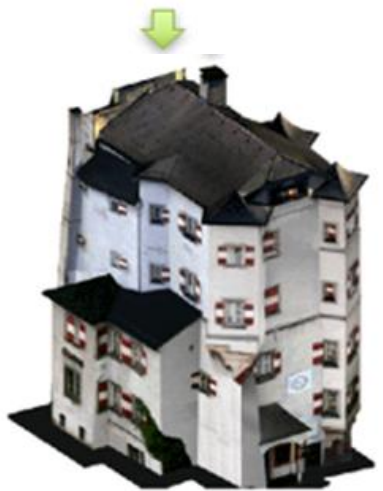

Figure 6: Using Architectural photogrammetry by GRUSSENMEYER "Ottoburg, Innsbruck ". (a.) inserting the images into the photogrammetry program. (b.)creating the elevations. (c.) creating the 3D model. 


\subsection{Historical Jeddah}

\section{THE CASE STUDY}

Most experts agree that the most significant source of culture and civilization is our past and heritage, which is often represented via buildings, music, language and habits.In fact, historical buildings represent many things from the past, such as the lifestyle, the economic conditions, social status and even, the climate. Besides, according to the ICOMOS, "Architecture is the most visible part of an occupation's history, and in many instances, has become an essential part of the urban and rural fabric of places around the world".

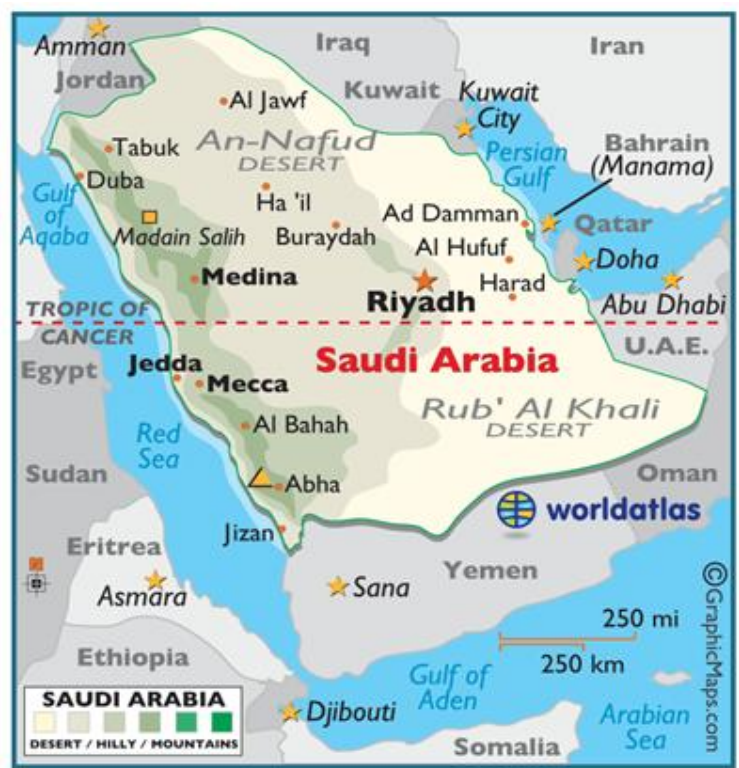

Figure 7: Location of Jeddah, Saudi Arabia (Source: Worldatlas.com, 2013)

Since the emergence of the UNESCO Convention in Paris 1972, the protection and conservation of cultural heritage have constituted a key pillar of sustainable development efforts. As such, many historical sites around the world have been documented, while some others have unfortunately been missed out, especially in developing and poorer countries. One of the unique heritage places which was not included in the UNESCO list was Historic Jeddah (TECTURAE, 2012).

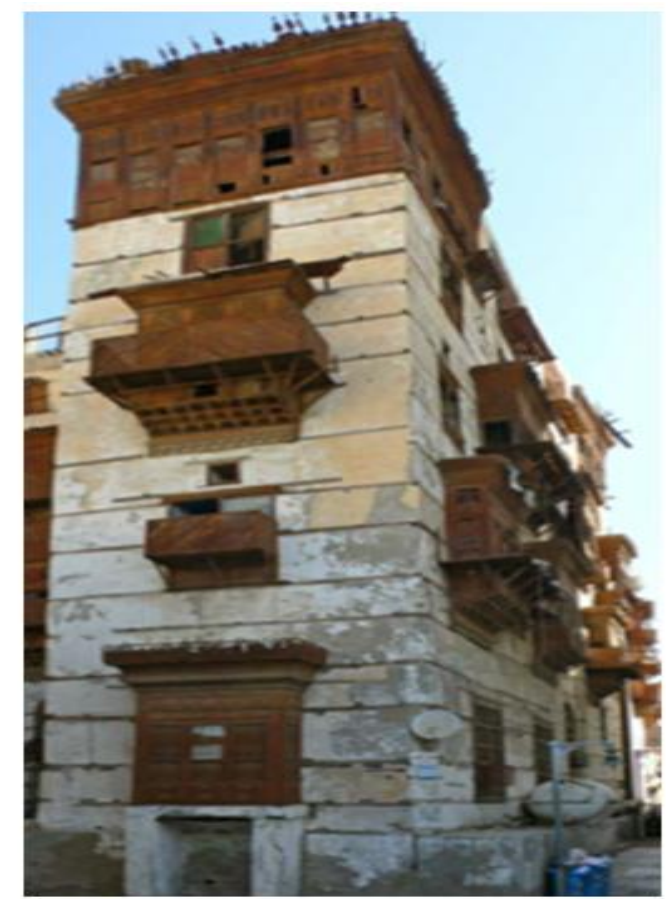

Figure 8: Jamjoum House, in Historic Jeddah. 
Jeddah is one of the most important cities in the Kingdom of Saudi Arabia. It is located in the western region of Saudi Arabia with a coastline on the Red Sea and is considered the economic and tourism capital of the Kingdom (Worldatlas.com, 2013).

The city has a long history as it dates back to 3000 years ago when groups of fishermen settled in the region after their fishing trips around the sea (Al-Fakahani, 2005).

Many of the buildings in Jeddah were built over 300 years ago, such as the "Nasif House" and "Jamjoum House". These buildings have special characteristics that originate from different aspects of Islamic culture (Telmesani et al., 2009).

\subsection{Cultural significance of the case study}

Nasif Historical House is one of the most famous houses in the historic district, which was built at the end of the $18^{\text {th }}$ century by Sheikh Omar Afandi Nasif, the agent of Jeddah for the Sharif of Makkah (Figure 10).

The main reason for the house's reputation is due to the fact that during the time when King Abdul-Aziz (Figure 9) entered Jeddah in 1925, he stayed in Nasif house, where he met the most notable people of Jeddah as the house was supposed to be the most distinguished and appropriate residence for the Sultan.

The architectural theme of Nasif house is similar to other historic Jeddah buildings with Roshans and Mashrabiyahs.

Until 1975, the house belonged to the Nasif family. One of the heirs, Sheikh Muhammad, turned Nasif House into a private library containing more than 16,000 books.

Today, Bayt Nasif has been restored and has become a museum and cultural centre (SCTA, 2013).
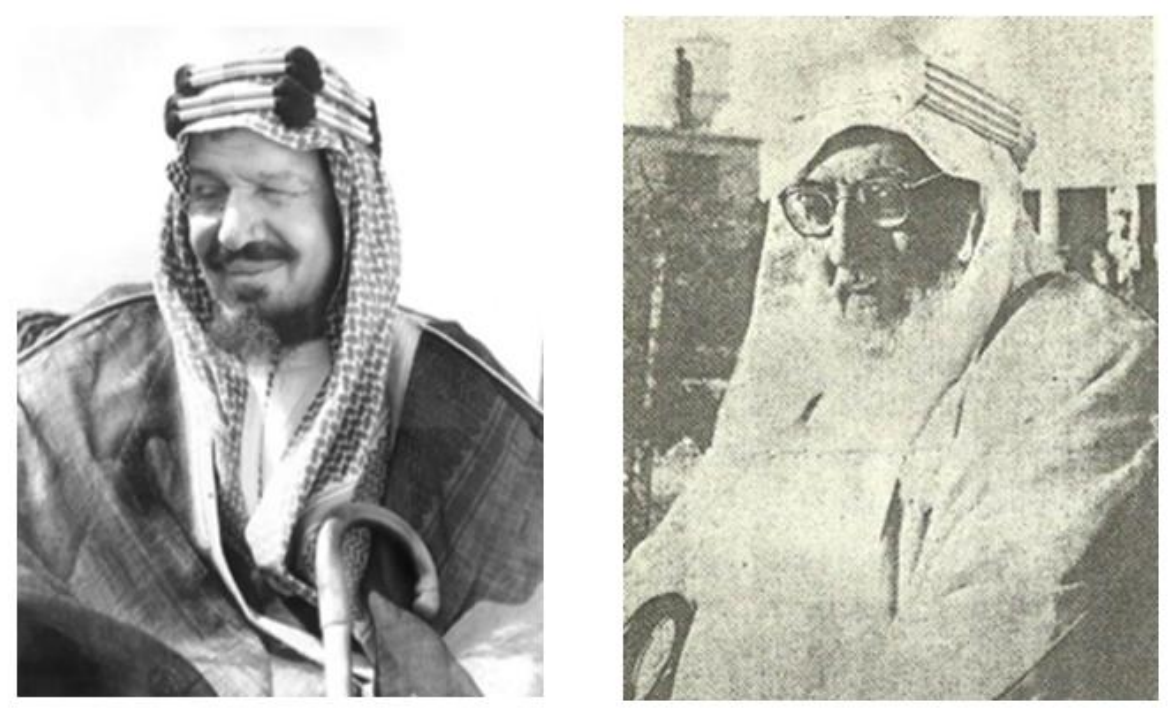

Figure 9: King Abdul-Aziz Al Saud.Figure 10: Sheikh Omar Afandi Nasif.

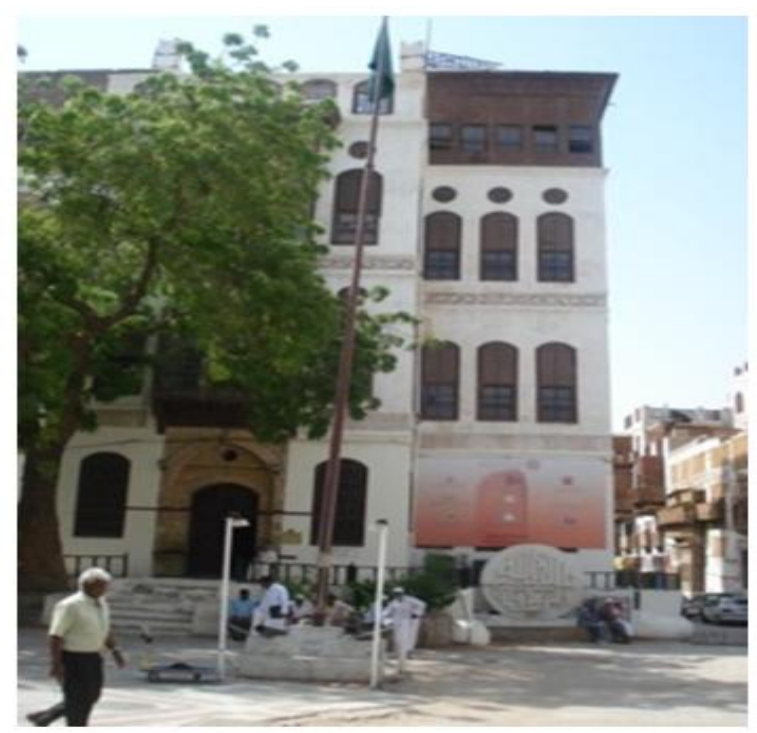

Figure 11: Nasif Historical House 


\subsection{Nasif Historical House description}

During the latter part of the $19^{\text {th }}$ century (the $13^{\text {th }}$ century, according to the Hijri calendar), the Nasif house was constructed. The house was constructed by Sheikh Omar Afandi Nasif, who started the building work in 1872 A.D. (1289 Hijri) and finished in 1881 A.D. (1298 Hijri). The man in charge of construction, Sheikh Omar Afandi Nasif, was a well-known person in the city and was held in great esteem. The Sultan of the Ottoman Empire, based in the city of Istanbul at the time, also rewarded Sheikh Omar Afandi Nasif with the award of "Vizier", as well as the awarding of the level of Mecca's Ameer's (Sharif "Awn) aide or spokesperson. The Nasif house is a clear representation of the stature of the person who built and owned it. The Nasif House also manages to capture the pinnacle of construction and building architecture at that point in time.

Nasif house comprises of four floors and has an architectural design that has identical dimensions, giving the Nasif House a very pleasing and aesthetic look. The Nasif House is situated right in the middle of the town. The external façade of the building is thoughtfully constructed with aesthetically created corners. The main attraction of the whole building is the beautiful woodcarvings on the main door, windows, and other wooden features. This carving has been done in impeccable quality wood that was brought into the city from eastern countries (Nawwar, 2013).

The vertical windows have been decorated with traditional glass work called the Mashrabiyah and are accompanied by shutters. The colour of the woodwork in the building is further enhanced by the faint colour of the building walls, providing a beautiful contrasting view. Apart from the fact that these windows have been aesthetically designed with meticulous woodwork, the louvered shutters also serve an important purpose as they allow for proper ventilation of the building, while also providing privacy for the occupants.

If someone is standing in the front of the building, he or she is bound to feel over-awed by the Roshan that spans two floors, starting from the main entrance gate and extending upwards (Figure 12).
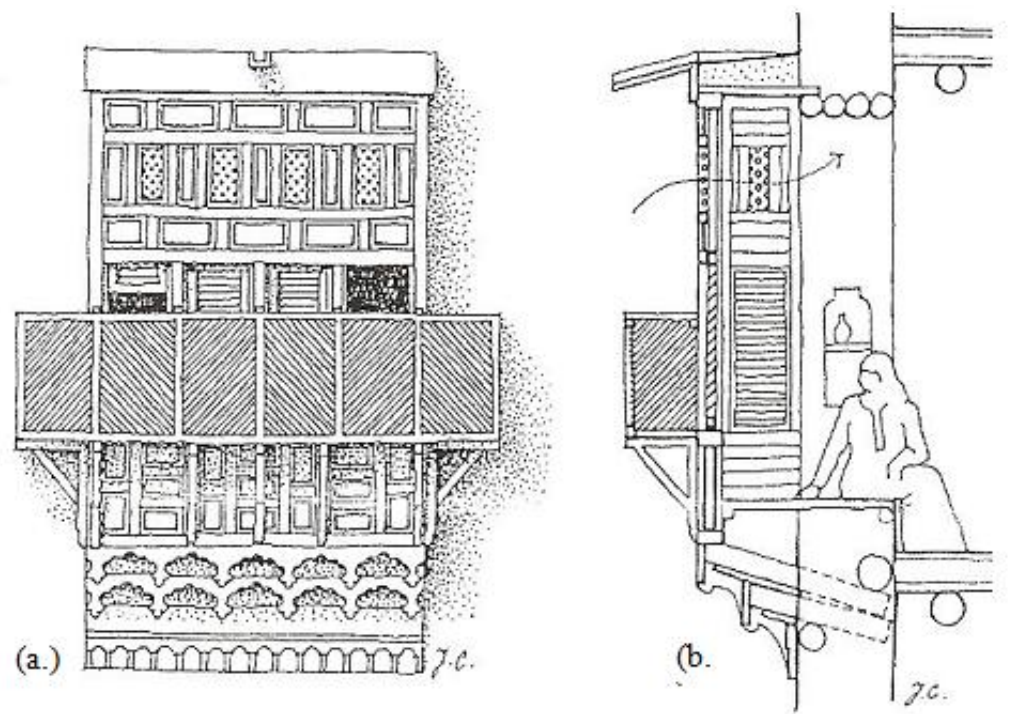

Figure 12: Detail of the Roshan window (Source: Ragette, 2003). (a.) Elevation of the Roshan. (b.) A section of the Roshan.

Alongside the large Roshan are the windows of the fourth story rooms with their beautiful, aesthetically pleasing, and meticulously carved woodwork. When viewed in conjunction, the Roshan and windows are a sight to behold.

Figure 13 shows the site plans of Nasif house. The inside of the building has also been carefully thought out and developed with big rooms in the centre, flanked by smaller living rooms on either side. The large twin flight of stairs are situated in the middle area of the back part of the building. The rooms for aides and servants are also situated at the back of the building. The second storey has a very beautifully designed place in the lobby, while the third story boasts a bathroom with a little dome in the ceiling, known as the Turkish bath (Figure 15). The fourth storey offers a huge terrace that extends in front of the central room, along with a kitchen situated at the back of this storey. Finally, the penthouse is constructed with fine woodcarvings that share their designs with those situated on the floor just below the penthouse.

Coral rocks extracted from the bed of the Red Sea have been carved in shapes with equal length and breadth before being used to construct the walls of the building (Figure 15). Plaster is used to smoothen out the look of the construction, while wood pieces are used at uniform distances in construction to lend further strength to the building's structure. 


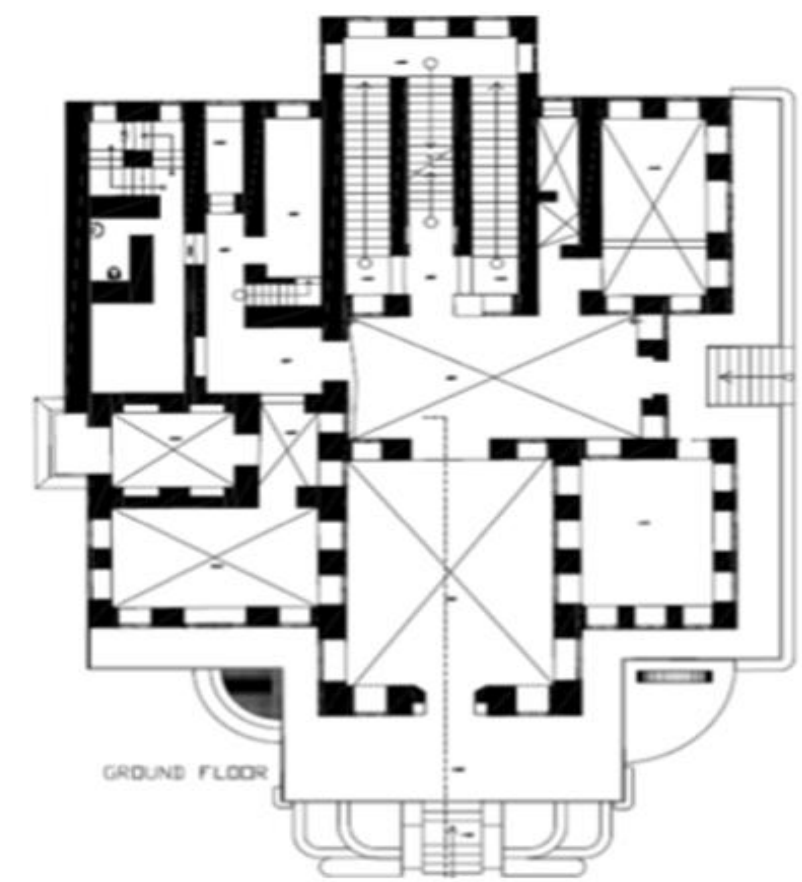

Figure 13: The ground floor of Nasif House.

The ground of every floor has been constructed using wooden beams. Mats made out of palm trees have been used, along with small stones and earth, in order to smoothen out and harden the flooring. Finally, to finish the flooring, screed has been poured over the floor. The eastern area of the south of the building features a utilities area. In the building, there are two floors that were built primarily to house different utilities, such as toilets, steps, storerooms, kitchens and so on.

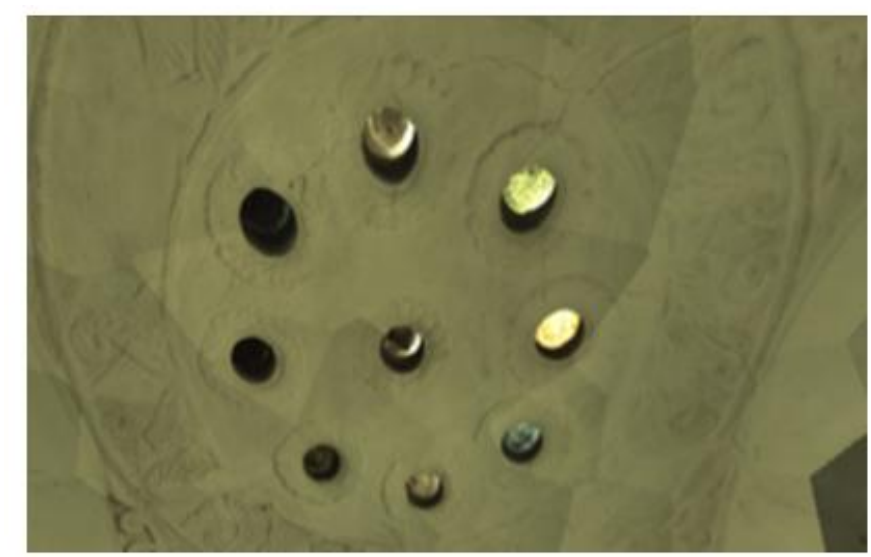

Figure 14: The Turkish bath at Nasif House.

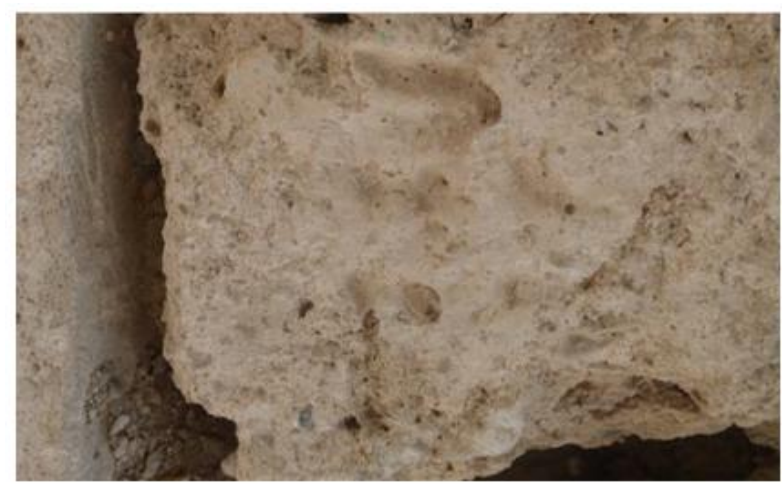

Figure 15: A coral block or in Arabic "Mangabi". 
The penthouse of the Nasif House is situated in the very middle of the roof and is adorned with beautiful carvings that share designs with the carvings done on the faces of the corner rooms on the fourth storey.

The staircase at the Nasif house is so colossal that it could easily be used in the past as a route for water carrying camels to reach the top floor. One of the grandsons of Muhammad Nasif remembers how his grandfather used to take his horse up to the top floors simply by riding the horse up the giant staircase.

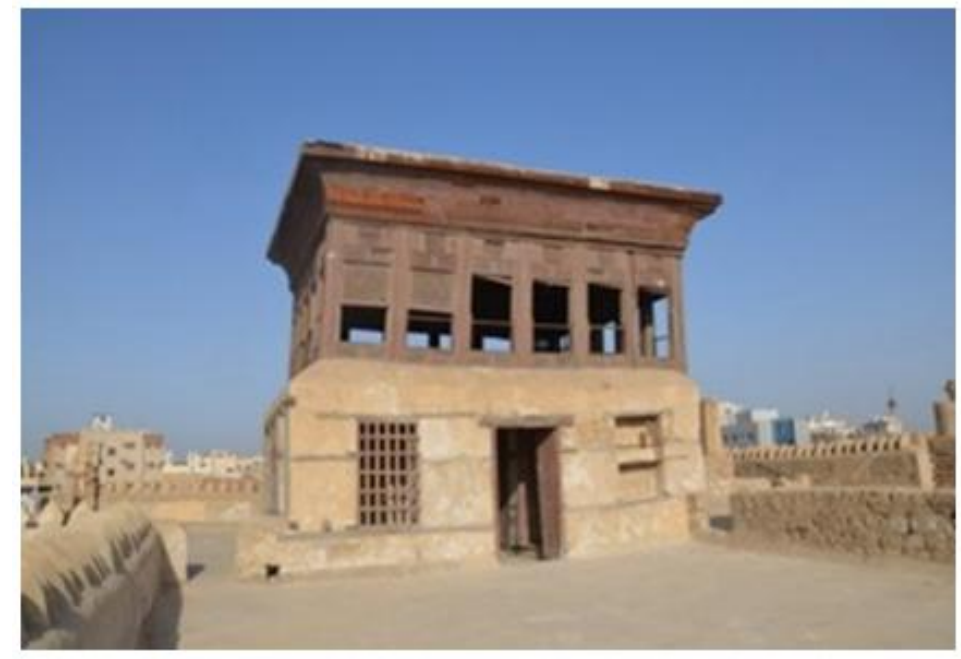

Figure 16: The penthouse.

\subsection{The Nasif Historical House: Issues}

The main question that faces the Nasif Historical House these days is how the municipality of Historical Jeddah can document, reconstruct and save the building in the view of a possible collapse or erosion due to environmental or human reasons and disasters as such fires. Presently, the Historical Jeddah Municipality is planning to reconstruct the building to be used as a historical museum of Jeddah (Nawwar, 2013).

\subsection{Aims}

In this project, the aim is to create full historical architectural documentation data of the Nasif Historical House by importing laser scanning survey data and image survey data. The outcome data could then be used as the base data for several applications for structural, architectural, constructional and other purposes.

\section{ON-SITE DATA ACQUISITION}

3.1 Technology, Programs and Equipment used

Nasif Historical House is unique andcomplex as it has alarge amount of Hijazi architectural detail. In order to build the model and coordinate it through the information for the historic house, the 3-D laser scanner has to generate 3-D point clouds, which forms the basis of the modelling process. This laser scanning procedure has many features, such as a field of view of $360^{\circ}$ in a horizontal direction and $270^{\circ}$ in a vertical direction, and this feature allows for the capturing of full panoramic views (Leica Geosystems, 2013).

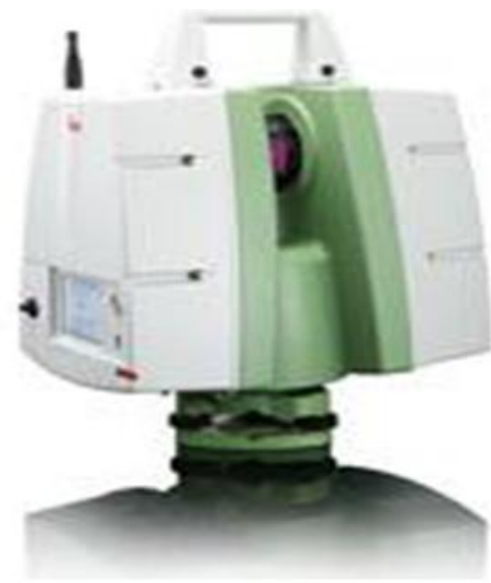

Figure 17: C10 scanner (Source: Leica Geosystems, 2013). 
Another feature of the scan method is described as a "time of flight dimension principle", which means that the Leica Scan-Station C10 can scan at ranges between $2 \mathrm{~m}$ up to $300 \mathrm{~m}$. The laser scanner has a mixed pixel clarifying framework; thus creating highly accurate point clouds which have X, Y and Z coordinates. The ScanStation C10 resolution and the spot size ranges from $0-50 \mathrm{~m}$ to $4.5 \mathrm{~mm}$ (FWHH- based) and $7 \mathrm{~mm}$ for (Gaussianbased). Besides, the accuracy of the single measurement for the position is $6 \mathrm{~mm}$ and for the distance is $4 \mathrm{~mm}$ at a $1 \mathrm{~m}$ to $50 \mathrm{~m}$ range. As with many modern laser scanning techniques, Leica $\mathrm{C} 10$ is provided with an internal HD camera. Besides, through the "Tru-view" feature, the LiDAR images can be presented, which can provide the ability to measure the building's dimensions.

In regard to the case study, to process the laser scanning point cloud, both Leica Cyclone ${ }^{\circledR}$ version 8.1.1 and Autodesk Recap pro software were used for the registration process and removing noise from the laser scanning data.

In addition, for the image survey step, a professional Nikon D5100, 18-mega pixel camera with an 18-55mm f/3.5-5.6 auto focus lens was used to capture the building's architectural features and details. Finally, Adobe Photoshop CS5® was used for the production of images.

\subsection{Images Survey}

To complete the documentation project, the on-site work began with the image survey step, which was intended to highlight and document the Hijazi architectural features for the Nasif Historical House.

The image survey of the house involved ten working days (from the $12^{\text {th }}$ to the $25^{\text {th }}$ of August 2014), and highlighted that the Nasif Historical House has very unique architectural features related to different Islamic cultures and ages, such as the Roshans and Mashrabiyahs, which were borrowed from the Ottoman culture (Figure18 shows some of Nasif house's architectural features).Through using professional software, such as Autodesk Recap, Autodesk memento and Agisoft Photo-scan, it is possible to use these images to build the 3-D mesh of the object. This process is known as architectural photogrammetry.

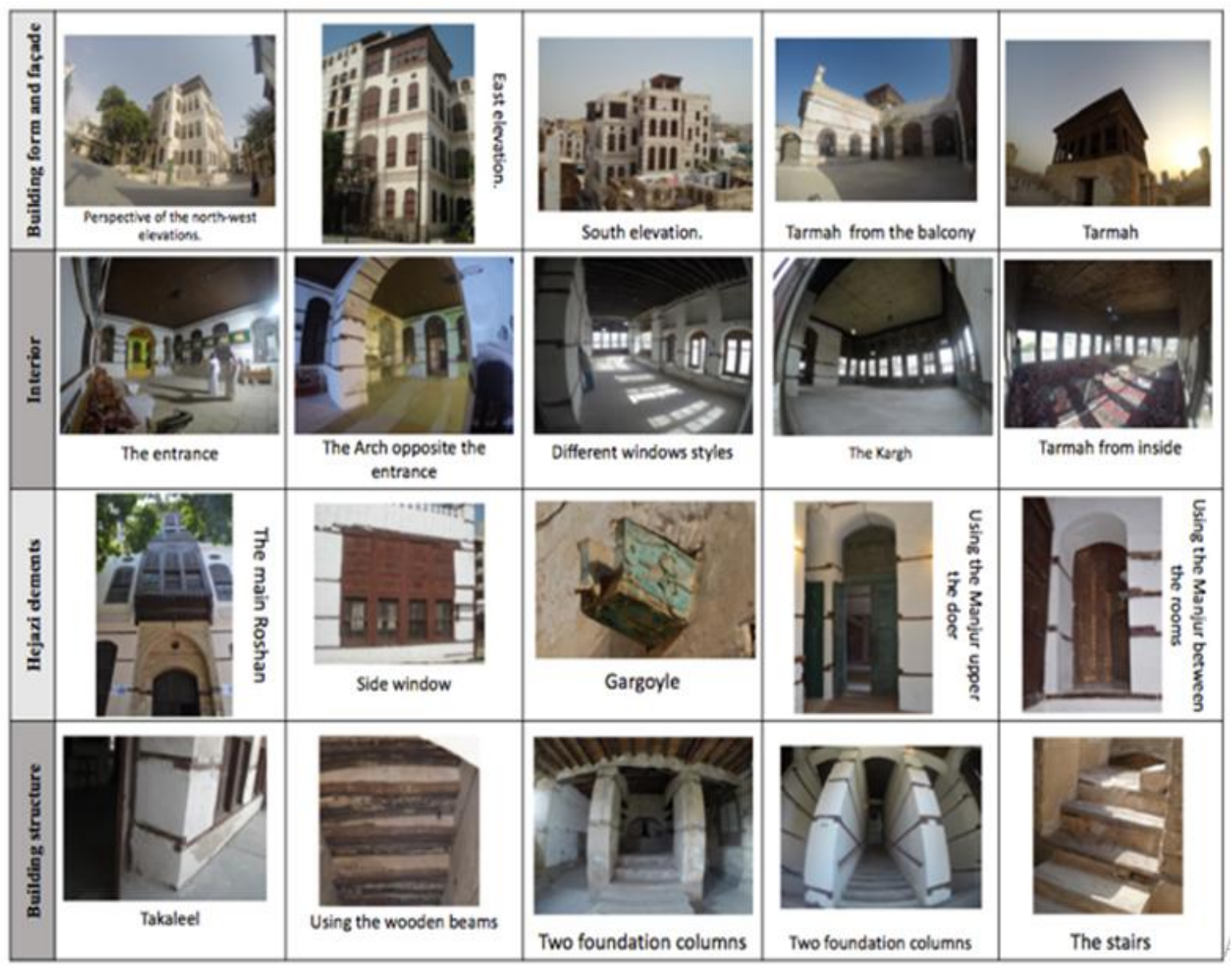

Figure 18: The image Survey "Freestyle" Method. 


\subsection{TLSSurvey}

The concept of remote data capture using terrestrial laser scanning, in addition to the processing of the point cloud data. This concept formed the basis of the initial elements for the documentation procedure. This procedure describes data acquisition based on the TLS and is followed by the data processing of point cloud data.

Employing the terrestrial laser scanning method involved initial preparation of the location in order to indicate the scan-station points to gain a good overlap between these scan-stations. Further, this was also undertaken in order to achieve high quality scanning, thus the HDS White and Black 'W/B' targets method was employed (Figure 19 shows the site preparation step) and about 400 'W/B' targets were used.

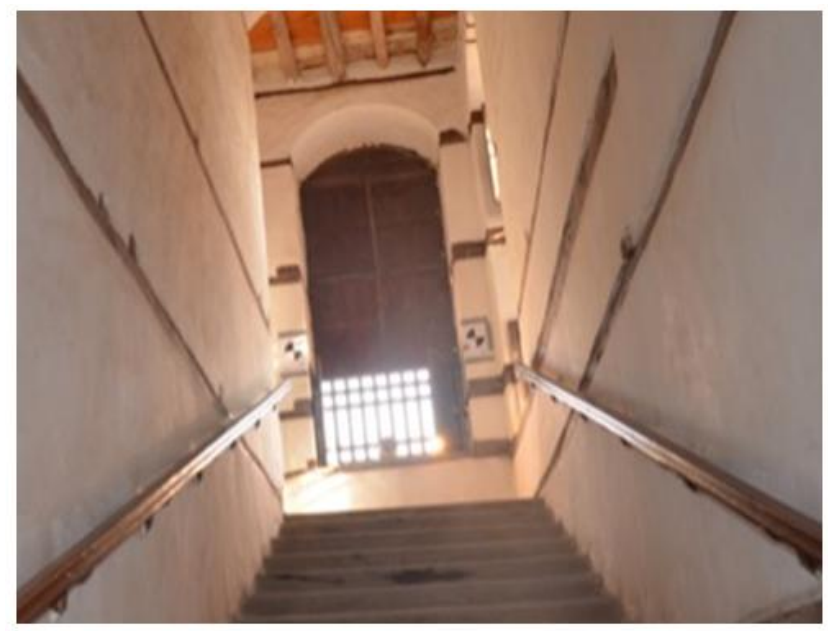

Figure 19: Locating the W/B targets on the wall of the staircase .

The preparation of the location lasted for more than five working days. To obtain a successful laser scanning survey, especially in the case of historical sites, it is very important to select the most suitable viewing locations, particularly since the amount of achievable scan-stations is normally limited due to the complexity of the structure and site.

Moreover, locating the targets on the staircase walls took more time as the house staircase targets, in this case, were used to registrant all the floors scans.

After preparing the location, the next step involved the laser scanning survey, and in order to obtain high accuracy in the laser survey, at least three $(\mathrm{W} / \mathrm{H})$ targets were needed to be in common with each of the overlapping scan-stations.

The scan-stations involved about 150 scans (overall, about 112 hours), which produced more than 70 GB of point cloud data with a resolution of $0.05 \mathrm{~m}$ and an average of $10 \mathrm{~m}$ distance inside the house, and up to $30 \mathrm{~m}$ outdoors.

The laser-scanning step took over ten working days to be completed (from the $16^{\text {th }}$ to the $30^{\text {th }}$ of August 2014).

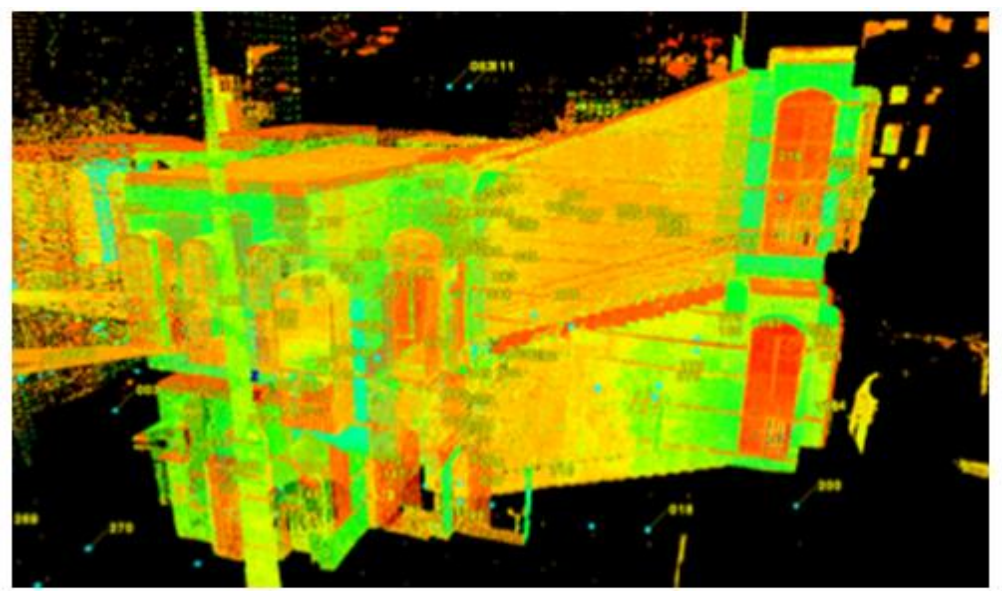

Figure 20: Using the staircase to link the floors' scans and to register the scans. 
The framework of the laser scanning survey is based on the following steps.

The first step: exploring the site and taking notes.

The second step: preparingthe site and determining the scan locations and the W/B targets' locations.

The third step: starting to collect the data using the Leica scan station C10 from inside to outside the house.

The fourth step: transferring the data to the desktop computer and preparing them for the next stage; "the point cloud prosecco and registration".

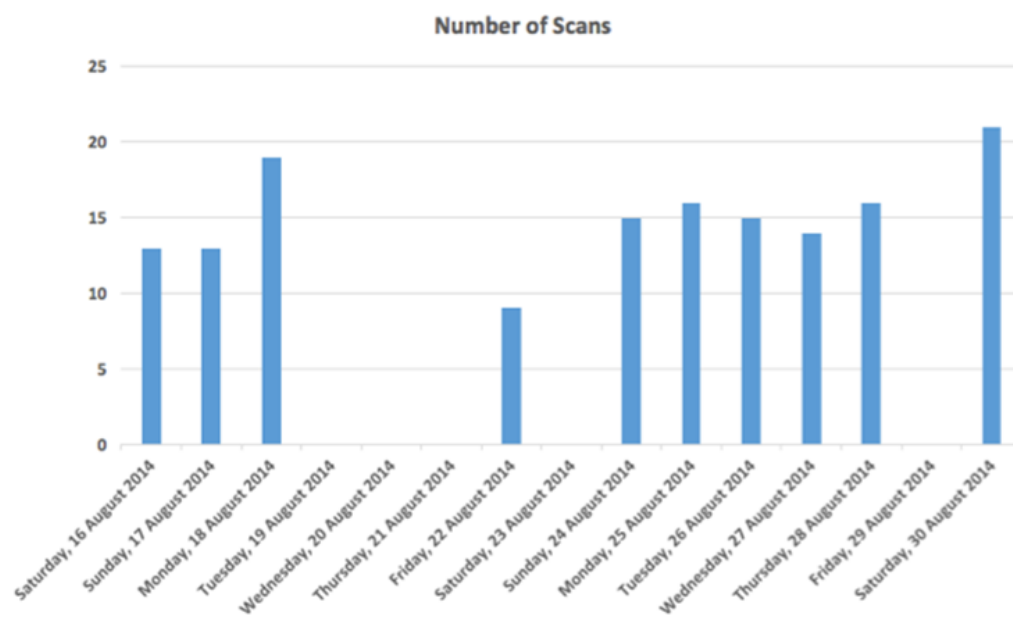

Figure 21: Graph illustrating the number of scans per day.

\subsection{TLSData Processing}

Following the data capture, the LiDAR model develops over a number of processing steps involving registering different scans, cleaning, and organising this point cloud data. The required 3-D point cloud models can be generated by using a number of software programs, such as Polyworks ${ }^{\circledR}$ software, Autodesk Recap® and Leica Cyclone®.
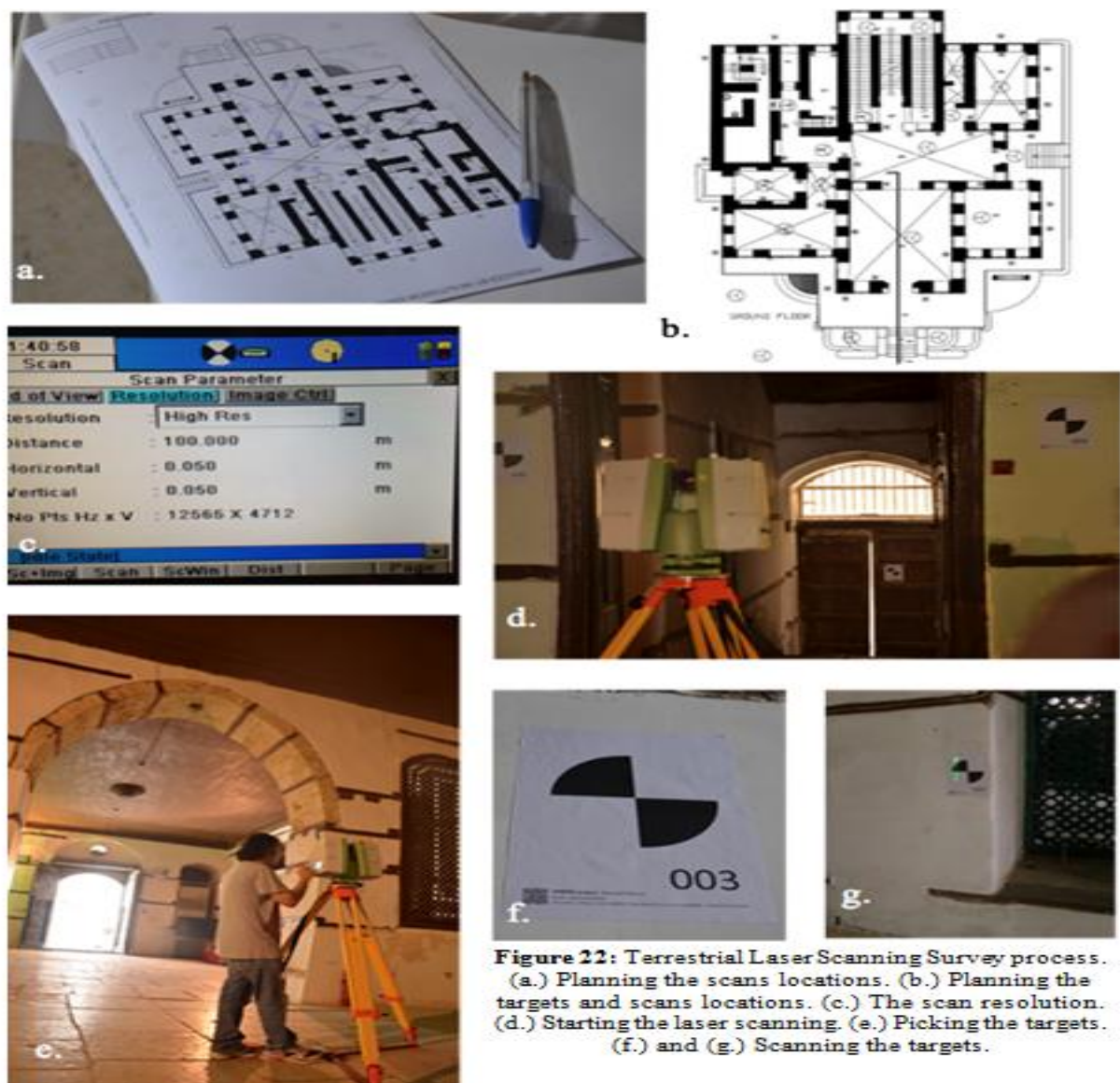

Figure 22: Terrestrial Laser Scanning Survey process. (a.) Planning the scans locations. (b.) Planning the targets and scans locations. (c.) The scan resolution. (d.) Starting the laser scanning. (e.) Picking the targets. 


\subsubsection{Point cloud registration}

In this case study, Leica Cyclone ${ }^{\circledR}$ 8.1.1 was initially used to register the scans. Several Scan-Worlds corresponding points in overlapping sections were linked for registration purposes. The point sets were registered in accordance with the coordination system and the elevation above sea level. This step, according to Attar et al. (2010), "allows for geo-referencing of the entire dataset by knowing the precise position of each point in terms of real-world coordinates".

Figure 23 shows more than three Scan-Worlds registrations that were collected for the Nasif Historical House. This step took around three days to be completed.

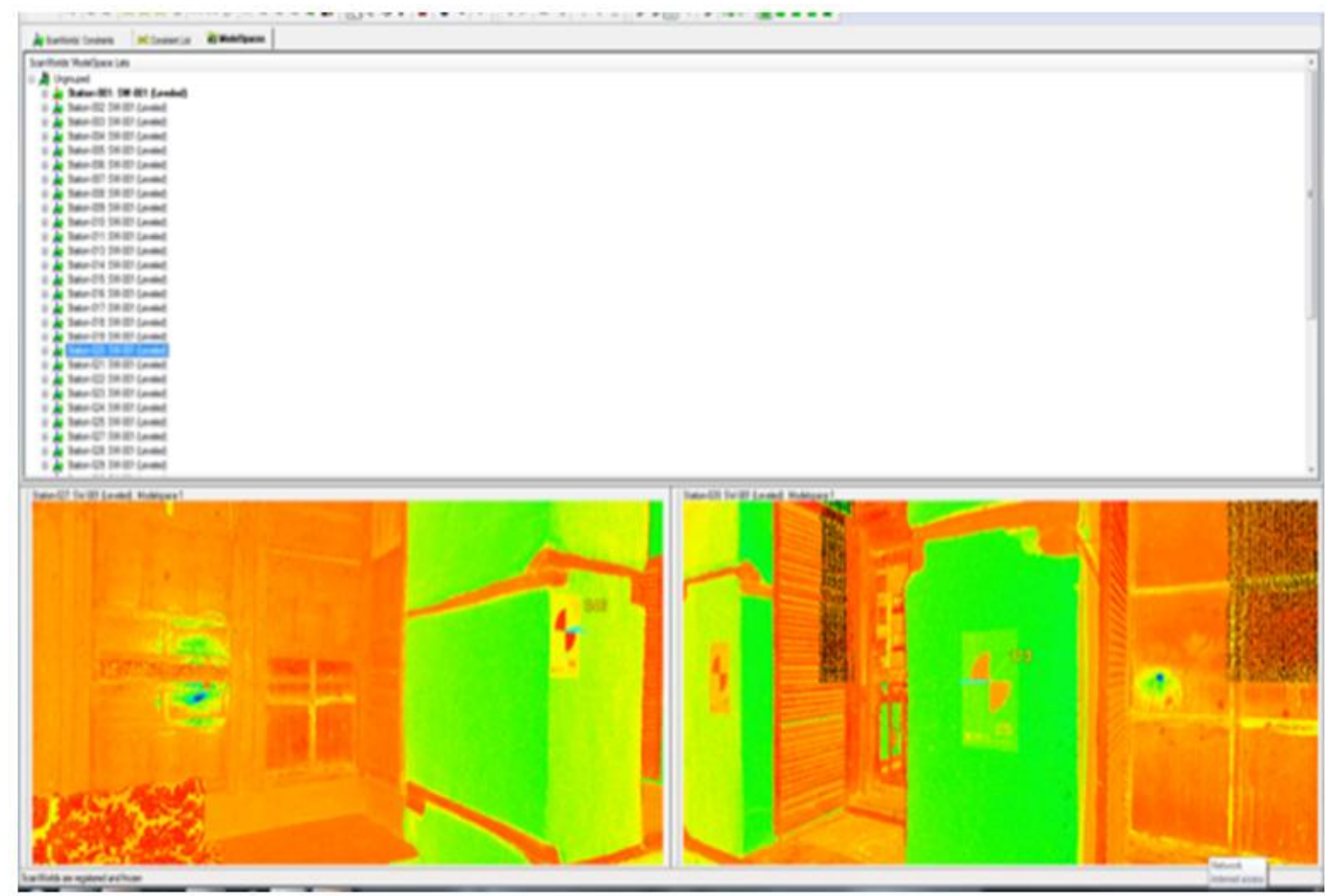

Figure 23: The Scan-Worlds registration for Nasif House project.

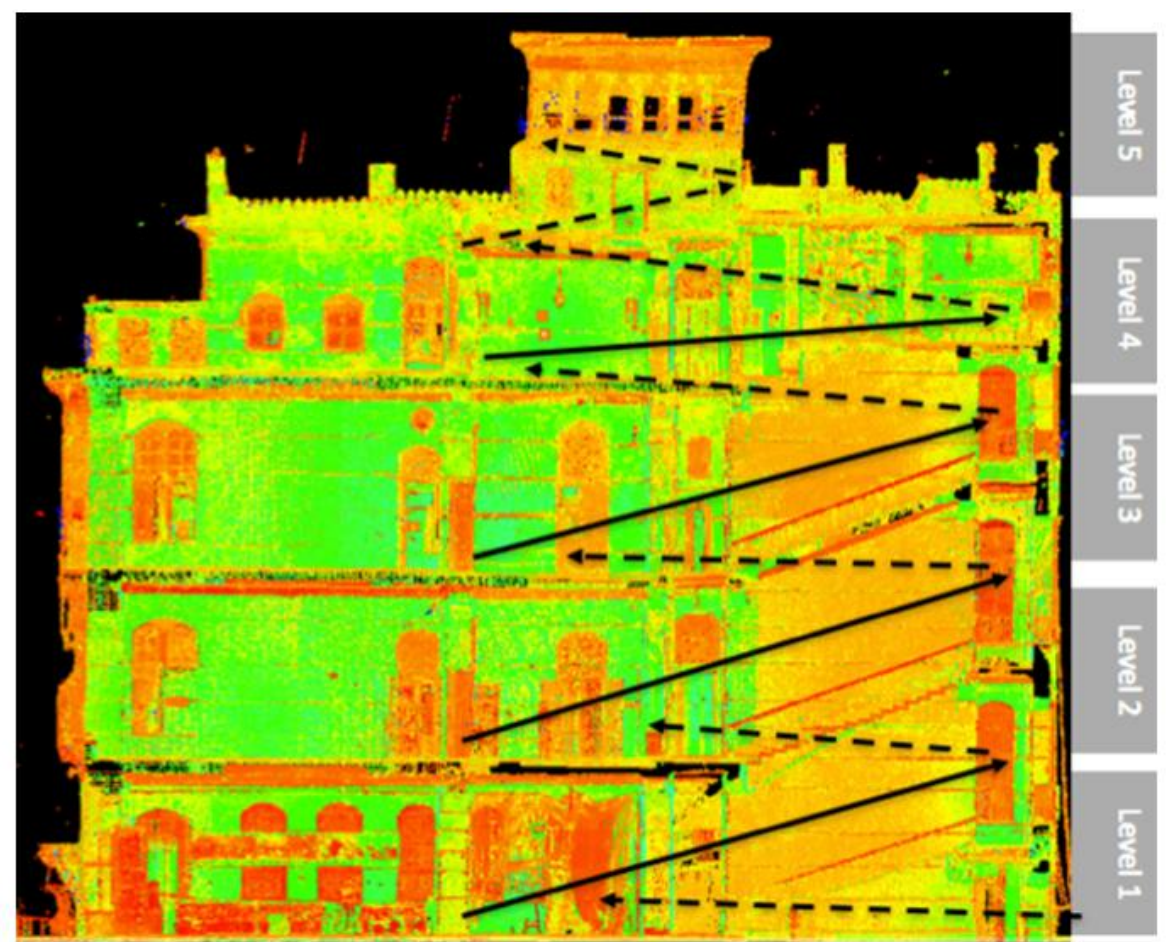

Figure 24: Section on the 3-D point cloud after using the staircase to link the floors' scans and to register the scans. 


\subsubsection{Point cloud data cleaning}

After the registration step, the Leica Cyclone ${ }^{\circledR}$ was used to remove noise from the registered 3-D point cloud (Figure 25) and completion of data processing required ten working days.

Figure 25 toFigure 27 show the resulting combinations of scans for the 3-D point cloud model, and the average resolution of the 3-D point cloud model of Nasif Historical House was $70 \mathrm{~mm}$ on the object surface.

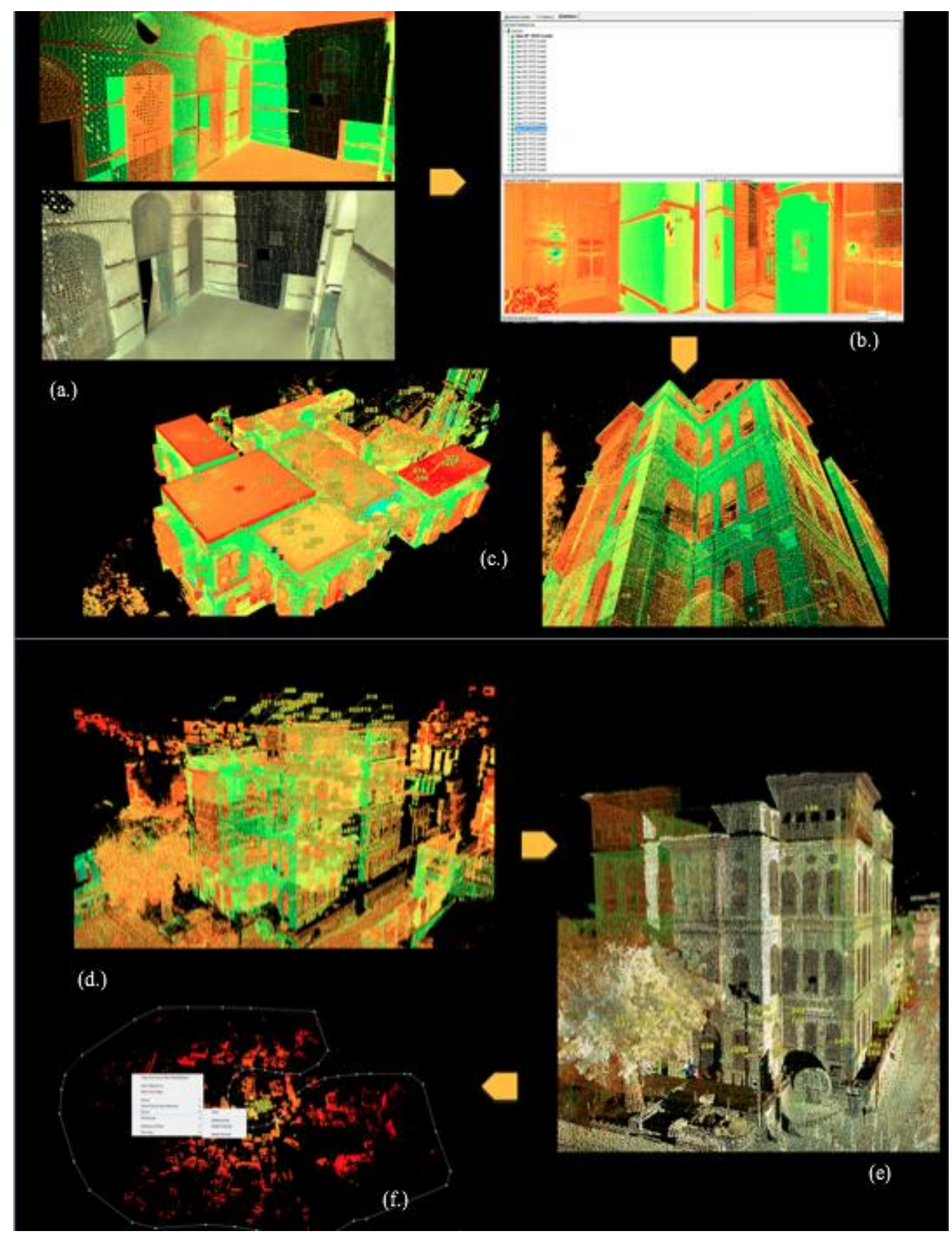

Figure 25: Point Cloud Data Processing for Nasif House. (a.) Point cloud with/without image texture map. (b.) Registration of the scans' point cloud. (c.) The results of the registration. (d.) The results of registration for all the scans. (e.) Applying the image texture map. (f.) Cleaning the noise. 


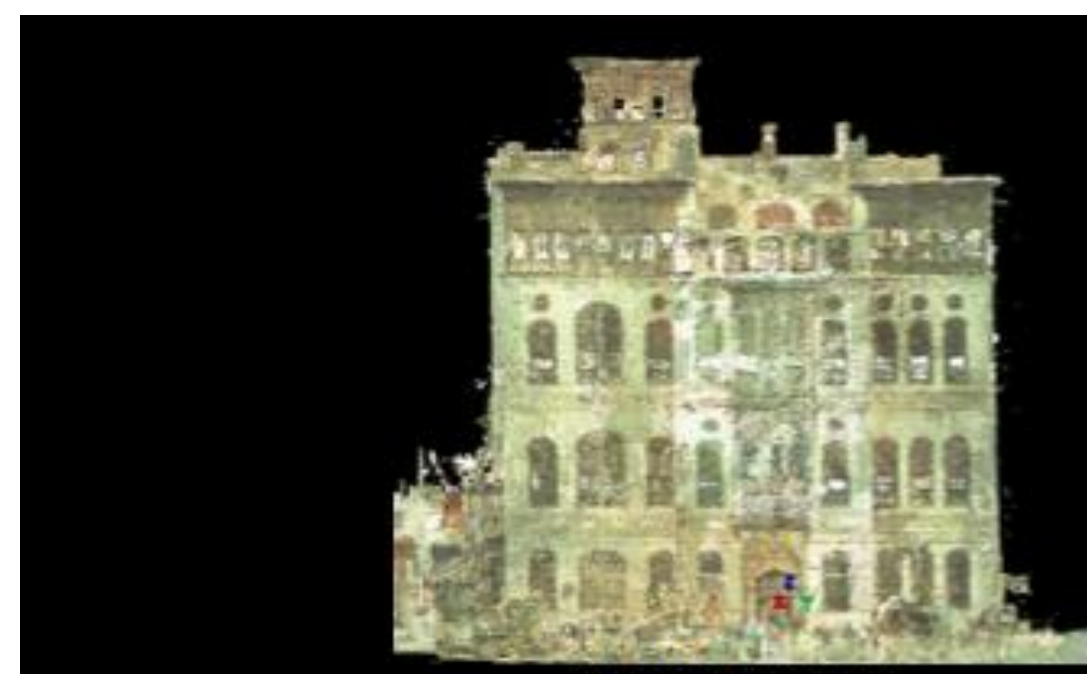

(a.) North Elevation

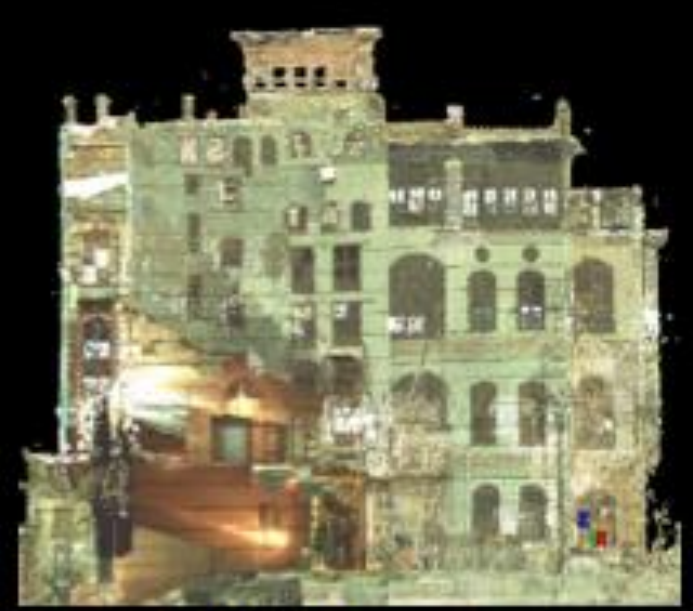

(b.) West Elevation

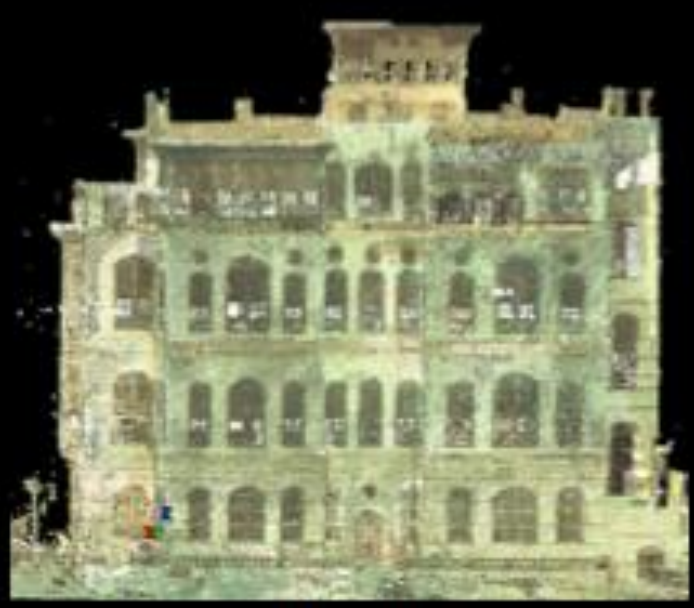

(c.) East Elevation

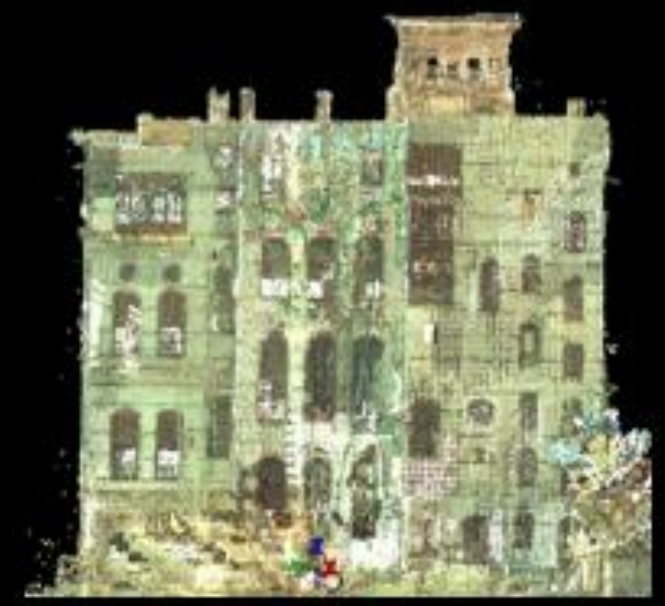

(d.) South Elevation

Figure 26: The resulting combinations of scans for the 3-D point cloud model. (a.) North elevation. (b.) West elevation. (c.) East elevation. (d.) South elevation. 


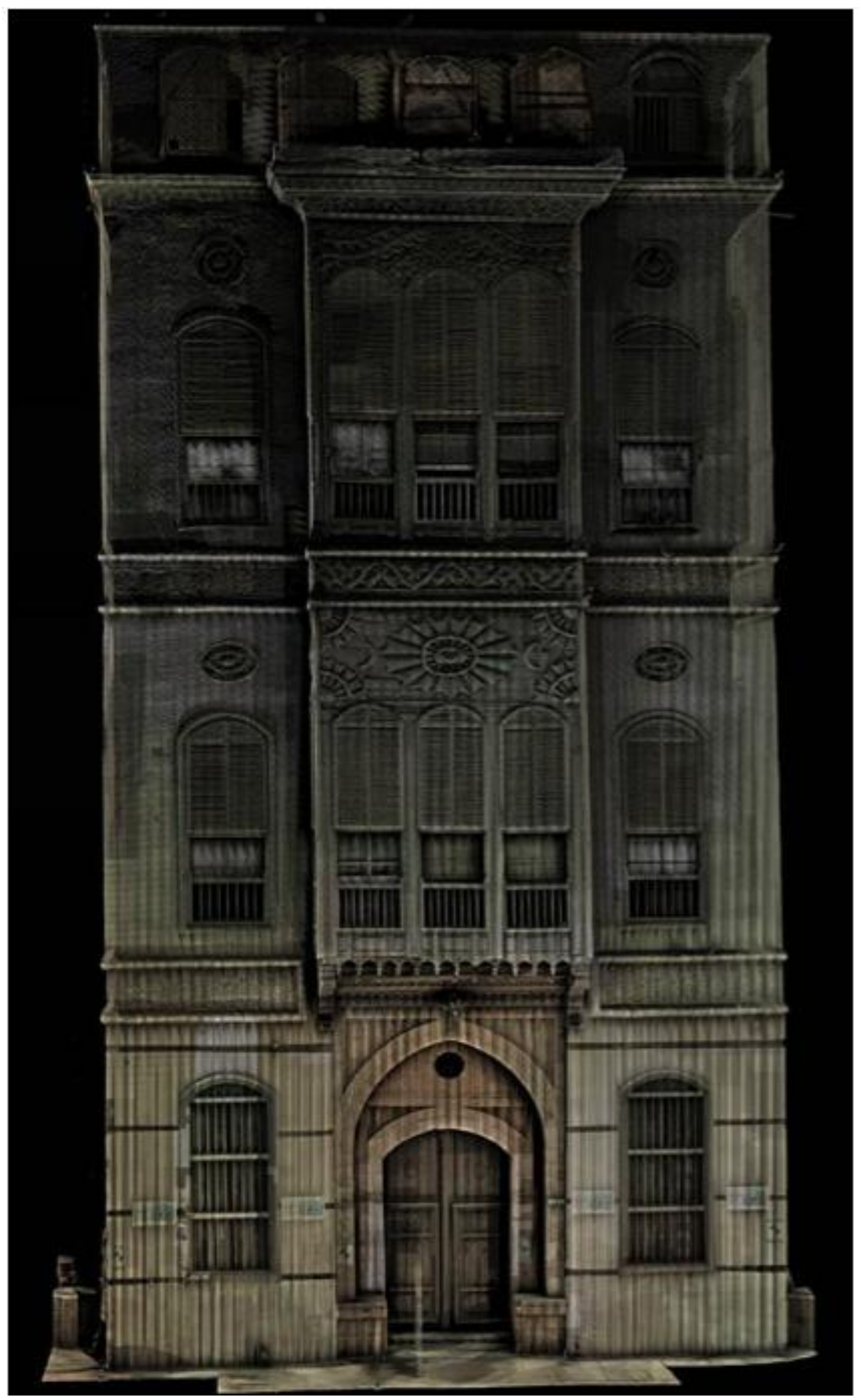

Figure 27: The laser scanning of the main Roshan in Nasif House (the colour is from the scanner). 


\section{Summary of the required output information are:}

a. A completed 3-D point cloud model of the whole building in (.rcp) file formats, indicating the plans, the elevations, structures "as it can be noticed" and 3-D;

b. Providing the architectural elements of the heritage building, which is unparalleled in the architectural libraries in (.rcp) file formats to be modelled separately which can be stored in the Hijazi architectural object library.

\section{CONCLUION AND FUTURE WORK}

This paper presented a framework for remote data capture using TLS and Photogrammetry survey. This framework demonstrated the initial elements for the next step, which would be Jeddah Heritage BIM (JHBIM). Furthermore, all extracted information from the constructed 3D models, such as maintenance activities, house structural condition, could be stored in the JHBIM database for spatial modelling and follow-up purposes. Additionally, through the outcome data from the JHBIM, we can decide which buildings need to be preserved, which cannot, and which must be destroyed. Finally, the 3D JHBIM models can be remotely reviewed in both their 'interior and exterior' with better understanding than that presented in 2D drawings.

\section{ACKNOWLEDGEMENT}

I honestly be grateful to the Almighty Allah "God" for seeing myself within this point of my life and I hope that Allah continues to guide and to direct me to the right. Besides, I hope that this work be useful for expert and any involved person in the field of heritage.

\section{REFERENCES}

[1]. Abdelhafiz, A., 2009. Integrating digital photogrammetry and terrestrial laser scanning. Techn. Univ., Inst. für Geodäsie und Photogrammetrie.

[2]. Abmayr, T., Härtl, F., Reinköster, M., Fröhlich, C., 2005. Terrestrial laser scanning-applications in cultural heritage conservation and civil engineering, in: Proceedings of the ISPRS Working Group V/4 Workshop 3D-ARCH 2005, Virtual Reconstruction and Visualization of Complex Architectures, International Archives of Photogrammetry, Remote Sensing and Spatial Information Sciences, Mestre-Venice.

[3]. Agarwal, S., Furukawa, Y., Snavely, N., Simon, I., Curless, B., Seitz, S.M., Szeliski, R., 2011. Building rome in a day. Commun. ACM 54, 105-112.

[4]. Al-Fakahani, H., 2005. Jeddah: The bridge of the red sea: Progress and development, The Arab Publishing House for Encyclopedias. Jeddah, KSA.

[5]. Alitany, A., REDONDO, E., Adas, A., 2013. The 3D Documentation of Projected Wooden Windows (The Roshans) in the Old City of Jeddah (Saudi Arabia) Using Image-based Techniques.

[6]. Arayici, Y., Khosrowshahi, F., Ponting, A.M., Mihindu, S., 2009. Towards implementation of building information modelling in the construction industry.

[7]. Attar, R., Prabhu, V., Glueck, M., Khan, A., 2010. 210 King Street: a dataset for integrated performance assessment, in: Proceedings of the 2010 Spring Simulation Multiconference. Society for Computer Simulation International, p. 177.

[8]. Backes, D., Thomson, C., Malki-Ephshtein, L., Boehm, J., 2014. Chadwick GreenBIM: Advancing Operational Understanding of Historical Buildings with BIM to Support Sustainable Use, in: Malki-Epsthein, L., Spataru, C., Marjanovic, L.H., Mumovic, D. (Eds.), . University College London.

[9]. Beraldin, J.-A., 2004. Integration of laser scanning and close-range photogrammetry-the last decade and beyond, in: International Society for Photogrammetry and Remote Sensing.

[10]. BIM Task Group, 2013. COBie UK 2012 [WWW Document]. BIMTaskGroup.org. URL http://www.bimtaskgroup.org/cobie-uk2012/

[11]. Boehler, W., Vicent, M.B., Marbs, A., 2003. INVESTIGATING LASER SCANNER ACCURACY. Presented at the XIXth CIPA SYMPOSIUM.

[12]. Budroni, A., Boehm, J., 2010. Automated 3D reconstruction of interiors from point clouds. Int. J. Archit. Comput. 8, 55-73.

[13]. Cheng, X.J., Jin, W., 2006. Study on reverse engineering of historical architecture based on 3D laser scanner, in: Journal of Physics: Conference Series. IOP Publishing, p. 843.

[14]. Cheok, G.S., Stone, W.C., Lipman, R.R., Witzgall, C., 2000. Ladars for construction assessment and update. Autom. Constr. 9, 463-477.

[15]. Darie, D., 2014. Building Information Modelling for museums (MSC in Surveying). University College London, London, U.K.

[16]. Furukawa, Y., Ponce, J., 2010. Accurate, dense, and robust multiview stereopsis. Pattern Anal. Mach. Intell. IEEE Trans. On 32, 1362-1376.

[17]. Hanke, K., Grussenmeyer, P., 2002. Architectural photogrammetry: Basic theory, procedures, tools, in: ISPRS Commission.

[18]. Heritage, E., 2011. 3D Laser Scanning for Heritage: Advice and guidance to users on laser scanning in archaeology and architecture, second edition. ed. English Heritage.

[19]. Hichri, N., Stefani, C., De Luca, L., Veron, P., 2013. Review of the «as-built BIM» approaches. ISPRS Arch. Photogramm Remote Sens Spat. Inf 107-112.

[20]. Hirschmuller, H., 2005. Accurate and efficient stereo processing by semi-global matching and mutual information, in: Computer Vision and Pattern Recognition, 2005. CVPR 2005. IEEE Computer Society Conference on. IEEE, pp. 807-814.

[21]. Huber, D., Akinci, B., Tang, P., Adan, A., Okorn, B., Xiong, X., 2010. Using laser scanners for modeling and analysis in architecture, engineering, and construction, in: Information Sciences and Systems (CISS), 2010 44th Annual Conference on. IEEE, pp. $1-6$.

[22]. Ikeuchi, K., 2001. Modeling from reality, in: 3-D Digital Imaging and Modeling, 2001. Proceedings. Third International Conference on. IEEE, pp. 117-124. 
[23]. Leica Geosystems, 2013. Leica ScanStation C10 [WWW Document]. URL http://hds.leica-geosystems.com/en/Leica-ScanStationC10_79411.htm (accessed 10.24.13).

[24]. Leica Geosystems, 2006. Inc. HDS Training Manual: Scanning \& Cyclone 5.4. 1. Leica Geosystems Inc San Ramon CA.

[25]. Macher, H., Landes, T., Grussenmeyer, P., Alby, E., 2014. Semi-automatic Segmentation and Modelling from Point Clouds towards Historical Building Information Modelling, in: Digital Heritage. Progress in Cultural Heritage: Documentation, Preservation, and Protection. Springer, pp. 111-120.

[26]. Mechelke, K., Kersten, T.P., Lindstaedt, M., 2007. Comparative investigations into the accuracy behaviour of the new generation of terrestrial laser scanning systems. Proc Opt. 319-327.

[27]. Mills, J., Barber, D., 2004. Geomatics techniques for structural surveying. J. Surv. Eng. 130, 56-64.

[28]. Murphy, M., 2013. Historic Building Information Modelling â€ “ Adding intelligence to laser and image based surveys of European classical architecture. ISPRS J. Photogramm. Remote Sens. 76, 89-102.

[29]. Murphy, M., 2012. Historic Building Information Modelling (HBIM) For Recording and Documenting Classical Architecture in Dublin 1700 to 1830 (Doctor of Philosophy thesis). Trinity College Dublin, Dublin.

[30]. Nawwar, S., 2013. Jeddah Historic Preservation Department, Jeddah Municipality.

[31]. Pfeifer, N., Böhm, J., 2008. Advances in Photogrammetry, Remote Sensing and Spatial Information Sciences: 2008 ISPRS Congress Book 7, 169-184.

[32]. Pollefeys, M., Nistér, D., Frahm, J.-M., Akbarzadeh, A., Mordohai, P., Clipp, B., Engels, C., Gallup, D., Kim, S.-J., Merrell, P., Salmi, C., Sinha, S., Talton, B., Wang, L., Yang, Q., Stewénius, H., Yang, R., Welch, G., Towles, H., 2008. Detailed Real-Time Urban 3D Reconstruction from Video. Int. J. Comput. Vis.

[33]. Rajendra, M.Y., Mehrotra, S.C., Kale, K.V., Manza, R.R., Dhumal, R.K., Nagne, A.D., Vibhute, A.D., 2014. EVALUATION OF PARTIALLY OVERLAPPING 3D POINT CLOUD'S REGISTRATION BY USING ICP VARIANT AND CLOUDCOMPARE. ISPRS-Int. Arch. Photogramm. Remote Sens. Spat. Inf. Sci. 1, 891-897.

[34]. Remondino, F., 2003. From point cloud to surface: the modeling and visualization problem, in: International Workshop on Visualization and Animation of Reality-Based 3D Models. p. 5.

[35]. SCTA, 2013. HISTORIC JEDDAH, THE GATE TO MAKKAH. SAUDI COMMISSION FOR TOURISM AND ANTIQUITIES, Saudi Arabia, Jeddah.

[36]. TECTURAE, I. design group, 2012. Al Balad Historic Dstrict Survey (Eng).

[37]. Telmesani, A., Sarouji, F., Adas, A., 2009. Old Jeddah A Traditional Arab Muslim City In Saudi Arabia, 1st ed. ed. King Fahad national library, Jeddah.

[38]. Thomson, C., Boehm, J., 2015. Automatic Geometry Generation from Point Clouds for BIM. Remote Sens. 7, $11753-11775$.

[39]. Thomson, C.P.H., 2016. From Point Cloud to Building Information Model: Capturing and Processing Survey Data Towards Automation for High Quality 3D Models to Aid a BIM Process. UCL (University College London).

[40]. Vergauwen, M., Van Gool, L., 2006. Web-based 3d reconstruction service. Mach. Vis. Appl. 17, 411-426.

[41]. Volk, R., Stengel, J., Schultmann, F., 2014. Building Information Modeling (BIM) for existing buildings-Literature review and future needs. Autom. Constr. 38, 109-127.

[42]. Worldatlas.com, 2013. Saudi Arabia Map / Geography of Saudi Arabia / Map of Saudi Arabia - Worldatlas.com [WWW Document]. URL http://www.worldatlas.com/webimage/countrys/asia/sa.htm (accessed 10.21.13). 